\title{
PENGARUH KUALITAS PRODUK DAN PELAYANAN TERHADAP LOYALITAS PELANGGAN PADA KEDAI ROTI BAKAR DI PAMULANG
}

\author{
Vera Ramadhanty¹, Delvira Juang Utami Putri², Fatimah Azzahra ${ }^{3}$ \\ Program Studi Ilmu Komunikasi, Sekolah Tinggi Ilmu Komunikasi LSPR \\ E-mail : vera.ramadhanty22@gmail.com ${ }^{1}$, juangvira@gmail.com², \\ fathimahbsa@gmail.com ${ }^{3}$
}

\begin{abstract}
Abstrak
Kedai Roti Bakar (KEIBAR) yang merupakan salah satu restoran yang menyediakan berbagai macam makanan terutama roti bakar yang mempunyai berbagai macam topping. Penelitian ini membahas antara kualitas produk dan pelayanan dengan loyalitas pelanggan. Dengan tujuan penelitian untuk mengetahui kualitas produk terhadap loyalitas pelanggan, pelayanan terhadap loyalitas pelanggan, kualitas produk serta pelayan terhadap loyalitas pelanggan, dan seberapa besar pengaruhnya di KEIBAR di Pamulang. Penelitian ini menggunakan metodelogi penelitian kuantitatif dengan objek penelitian yaitu pada Kedai Roti Bakar (KEIBAR) di Pamulang dengan melihat seberapa loyal konsumen untuk datang ke KEIBAR serta dengan melihat kualitas produk (X1) dan pelayanan (X2). Jenis penelitian ini menggunakan korelasional yang bertujuan untuk menjelaskan hubungan antara kualitas produk dan pelayanan dengan loyalitas pelanggan pada KEIBAR di Pamulang. Penelitian ini menggunakan sampel sebanyak 254 responden dari jumlah populasi 700 pelanggan. Teknik sampling yang digunakan pada penelitian ini adalah purposive sampling, nonprobability sampling dengan metode accidental sampling. Penelitian ini menggunakan 7 uji instrumen yaitu uji validitas, uji reliabilitas dan uji normalitas, uji korelasi berganda, uji asumsi klasik (multikolnearitas), uji anova serta dilakukan uji analisis regresi linier berganda. Hasil dari penelitian ini menunjukkan bahwa kualitas produk dan pelayanan memiliki hubungan yang kuat terhadap loyalitas pelanggan dengan nilai regresi 0,634.
\end{abstract}

Key Words: Kualitas Produk, Pelayanan, Loyalitas Pelanggan, Perilaku Konsumen

\begin{abstract}
Kedai Roti Bakar (KEIBAR) which is one of the restaurants that provides a variety of foods, especially toast with a variety of toppings. This study discusses the quality of products and services with customer loyalty. With the aim of research to determine product quality on customer loyalty, service to customer loyalty, product quality and service to customer loyalty, and how much influence on KEIBAR in Pamulang. This research uses quantitative research methodology with the object of research that is at Kedai Roti Bakar (KEIBAR) in Pamulang by seeing how loyal consumers are to come to KEIBAR and by looking at product quality (X1) and service (X2). This type of research uses correlation which aims to explain the relationship between product quality and service with customer loyalty at KEIBAR in Pamulang. This study used a sample of 254 respondents from a population of 700 customers. The sampling technique used in this study was purposive sampling, non-probability sampling with accidental sampling method. This research uses 7 test instruments, namely the validity test, reliability test and normality test, multiple correlation test, classic
\end{abstract}


assumption test (multicollinearity), ANOVA test and multiple linear regression analysis test. The results of this study indicate that the quality of products and services has a strong relationship with customer loyalty with a regression value of 0.634 .

Kata Kunci: Product Quality, Service, Customer Loyalty, Consumer Behavior

\section{PENDAHULUAN}

Saat ini perkembangan bisnis di dalam bidang kuliner semakin tinggi, sebabnya sudah banyak sekali orang yang membangun bisnisnya di bidang kuliner. Bahkan restoran ini sudah dipenuhi ataupun dicari oleh para kalangan anak - anak muda. Anak muda kini sudah menjadi salah satu target pelanggan yang harus dipenuhi kebutuhan dan juga keinginannya oleh perusahaan,oleh sebab itu ini merupakan salah satu syarat yang harus dipenuhi oleh perusahaan agar dapat mencapai tujuan untuk menciptakan dan mempertahankan pelanggan. Menurut Kotler (2005) dalam (Aryani \& Rosinta, 2010, p. 115), semakin tingginya persaingan akan menyebabkan pelanggan mengalami banyak alternatif produk, harga dan kualitas yang bervariasi sehingga pelanggan akan terus mencari nilai yang dianggap paling tinggi dari produk tersebut.

Apabila konsumen merasa puas terhadap suatu produk yang dibeli, akan menimbulkan kesetiaan membeli sehingga membuat pembeli melakukan pembelian ulang dimasa yang akan datang (Putro, Semuel, \& Brahmana, 2014, p. 1). Maka sebuah kedai ataupun restoran harus selalu membuat pembaharuan terhadap produk yang akan dijualnya agar para pelanggan bisa melakukan repurchase terhadap produk tersebut. Dengan pembelian secara berulang maka seseorang akan menjadi pelanggan yang loyal terhadap suatu produk tersebut ataupun loyal dengan tempat dia membeli produk sehingga para pelanggan dapat menceritakan kembali mengenai kualitas produk serta pelayanan kepada orang lainnya. Loyalitas menggambarkan bagaimana seorang pelanggan akan beralih untuk ke tempat lainnya yang lebih baik jika tempat itu membuat suatu perubahan pada kualitas produk dan pelayanannya.

Pelanggan sendiri akan terus menerus untuk datang secara berulang ke suatu tempat yang sama guna memuaskan keinginan dengan mendapatkan suatu produk dan pelayanan yang diinginkan sesuai dengan ekspetasi yang diharapkan. Menjadi seorang pelanggan yang loyal tidak dapat terjadi secara instant sebab ada beberapa tahap yang harus dilakukan jika ingin konsumen menjadi loyal seperti perusahaan harus bisa mengikuti ekspetasi yang diharapkan pelanggan . Seorang pelanggan akan terus merasa puas terhada pelayanan yang diberikan dan akan terus meningkat dengan cara membuat pelanggan menjadi loyal terhadap produk tersebut. Selain itu, sebuah perusahaan juga harus lebih memperhatikan apabila terjadinya seuah penurunan dari jumlah pelanggan karena beralihnya mereka kepada perusahaan lain karena ketidakpuasan terhadap kualitas dari produk ataupun layanan yang diberikan perusahaan.

Menurut Kotler dalam Hardiyansyah (1997) "Kualitas adalah keseluruhan ciri serta sifat dari suatu produk atau pelayanan yang berpengaruh pada kemampuannya untuk memuaskan kebutuhan yang dinyatakan atau tersirat, kualitas tidak dapat dipisahkan dari produk dan jasa atau pelayanan" (Hardiyansyah, 2018, p. 49). Dalam hal ini berarti kualitas dapat mempengaruhi performa dari perusahaan itu sendiri. Salah satu keunggulan dalam persaingan 
adalah kualitas produk yang dapat memenuhi kebutuhan/keinginan pelanggan. Jika tidak sesuai dengan ekspetasi tersebut maka produk dapat ditolak. Kondisi ini menuntut perusahaan untuk dapat terus mempertahankan dan meningkatkan inovasi dari produknya agar terhindar dari ketidakpuasan pelanggan.

Menurut (Tjiptono, 2015, p. 231) "Produk merupakan segala sesuatu yang dapat ditawarkan produsen untuk diperhatikan, diminta, dicari, dibeli, digunakan, dan/atau dikonsumsi pasar sebagai pemenuhan kebutuhan atau keinginan pasar bersangkutan". Dapat diuraikan bahwa customer tidak hanya membeli barang yang berwujud seperti, pakaian, makanan tetapi juga membeli sesuatu yang dapat dimanfaatkan sebagai pemenuh kebutuhan sehari - hari. "Kualitas produk dan jasa, kepuasan pelanggan, dan profitabilitas perusahaan adalah tiga hal yang terkait erat. Semakin tinggi pula tingkat kualitas, semakin tinggi tingkat kepuasan pelanggan yang dihasilkan, yang mendukung harga yang lebih tinggi (sering kali) biaya yang lebih rendah" (Kotler \& Keller, 2009, p. 144).

Dalam hal ini pelayanan juga menjadi sangat penting bagi suatu perusahaan untuk meningkatkan kinerja perusahaan tersebut pasalnya saat ini sudah banyak pesaing yang mempunyai perusahaan sejenis yang juga menawarkan pelayanan yang lebih baik. "Pelayanan yang berkualitas dan memuaskan pelanggan perlu dilakukan secara terus menerus walaupun pengaduan untuk komplain tamu sangat relatif rendah. Namun dapat di tunjukan bahwa pelanggan yang mengadu akan menjalin hubungan bisnis kembali dengan perusahaan jika diberikan jalan penyelesaian yang baik. Pelayanan merupakan kunci sukses oleh karena itu kualitas jasa harus menjadi fokus utama perhatian bagi manajemen dalam menjalankan usahanya" (Rusydi, 2017, p. 85).

Menurut (Kennedy \& Soemanagara, 2009, p. 5) "Marketing Communication adalah kegiatan ppemasaran dengan menggunakan teknik - teknik komunikasi komunikasi yang bertujuan untuk memberikan informasi pada orang banyak yang bertujuan untuk memberikan informasi pada orang banyak agar tujuan perusahaan tercapai, yaitu terjadinya peningkatan pendapatan atas penggunaan jasa atau pembelian produk yang ditawarkan". Seperti yang disudah dijelaskan sebelumnya bahwa komunikasi pemasaran juga dapat berhubungan dengan kualitas produk serta pelayanan dan loyalitas dikarenakan sebuah restoran harus mengupayakan kualitas dari setiap produknya dan juga pelayanan yang maksimal seperti 3S ( Senyum, Sapa, dan Salam) sehingga dapat menghasilkan pelanggan yang loyal.

Dalam penelitian ini peneliti melakukan penelitian mengenai Kedai Roti Bakar atau yang sering disebut dengan KEIBAR ini merupakan sebuah kedai atau tempat makan yang pertama berdiri di Pamulang sejak 2013. KEIBAR ini menyajikan berbagai macam makanan maupun minuman yang sangat bervariasi tidak hanya menjual roti saja seperti namanya tetapi terdapat juga menu seperti mie instant maupun nasi goreng. Kedai ini juga menjadi salah satu tempat berkumpul untuk anak - anak muda yang tinggal di daerah Pamulang tersebut. Berdasarkan pra penelitian yang dilaksanakan pada 23 Oktober 2018 terhadap beberapa pelanggan yang ada di Keibar tersebut mengatakan bahwa kualitas produk dengan berbagai menu perlu ditingkatkan dikarenakan menu yang hanya itu saja, tetapi untuk kebersihan sangat baik dan beberapa makanan mempunyai cita rasa tersendiri. Untuk pelayanannya pun beberapa pelanggan mengatakan bahwa mereka senang karena pelayan yang begitu ramah dan sopan ketika menyambut kedatangan pelanggan, tetapi mereka mengatakan bahwa karena Keibar itu selalu ramai apalagi saat weekend mereka juga harus menunggu lama (waiting list) demi 
mendapatkan tempat duduk yang ada di KEIBAR tersebut. Sehingga bagaimana cara mempertahankan para pelanggan agar loyal dengan usaha yang dibangun, dengan memiliki pelanggan yang loyal usaha ini pasti akan memenangkan persaingan dengan para kompetitor lainnya. Untuk mendapatkan pelanggan yang loyal dengan suatu usaha tidak mudah maka pemilik usaha atau penjual tersebut harus bisa membuat para pelanggan merasa puas dan juga nyaman.

\section{KERANGKA TEORI}

Komunikasi Pemasaran. Menurut Uyung Sulaksana, 2005 (dalam Tjiptono, 2011) menyatakan bahwa komunikasi pemasaran adalah proses penyebaran informasi tentang perusahaan dan hal - hal yang akan ditawarkan kepada sasarannya. Komunikasi pemasaran merupakan aktivitas pemasaran yang berusaha menyebarkan informasi, mempengaruhi/membujuk, mengingatkan pasar sasaran atas perusahaan dan produknya agar bersedia menerima, membeli, dan loyal pada produk yang ditawarkan perusahaan yang bersangkutan (Priansa, 2017, p. 96).

Komunikasi pemasaran sangat penting bagi sebuah perusahaan untuk memberikan suatu informasi terutama dalam bauran pemasaran (marketing mix) yang mempunyai tujuh komponen yaitu, product, price, place, promotion, physical evidance, people, and process. Dalam hal ini produk menjadi salah satu komponen yang paling penting dalam suatu strategi perusahaan yang dapat memuaskan segmen pasar yang dijadikan sasaran untuk suatu produk guna menarik konsumen untuk melakukan pembelian secara berulang sehingga merekan akan tetap loyal terhadap produk serta perusahaan tersebut.

Perilaku konsumen. Perilaku Konsumen sangat berpengaruh bahkan sangat menguntungkan dengan mengetahui sikap seseorang dimana dalam hal ini diketahui bahwa perusahaan dapat mengetahui apa yang diinginkan atau dibutuhkan dari seorang pelanggan agar dapat memenuhi kebutuhan dari perusahaan tersebut, karena dari itu perusahaan perlu tahu seperti apa sikap dari seorang pelanggan untuk dapat memuaskan kebutuhannya. Seperti apa yang diutarakan oleh (Sudaryono, 2014, p. 11), merupakan landasan perilaku konsumen merupakan hal yang sangat penting untuk menyusun strategi pemasaran opersaionalisasi penjualan dengaan memahami perilaku konsumen pelaku usaha mampu mengklasifikasikan konsumen berdasarkan usia, jeis kelamin, jenis pekerjaan dan tingkat pendidikan.

Kualitas Produk. Menurut (Wijaya, 2018, p. 32), kualitas produk dapat dijelaskan dan dikomunikasikan menurut harapan pelanggannya yang dimana semua periklanan, penjualan, promosi dan layanan pelanggan tidak banyak membantu dari kualitas produk yang buruk, untuk menghindarkan hal tersebut maka perusahaan bekerja setiap hari untuk memeriksa setiap produk yang dipesan untuk menjamin dan meyakinkan bahwa tidak akan terjadi masalah pada kualitas produkyang dapat menentukan nama baik dari perusahaan.

Dimensi Kualitas Produk. Menurut (Shaharudin, Mansor, dan Elias, 2011) dalam (Yafie, Suharyono, \& Abdillah, 2016, p. 13) yang digunakan untuk mengukur kualitas produk makanan (food quality) terdapat empat dimensi, yang antara lain adalah freshness (kesegaran), presentation (tampilan), taste (rasa), dan innovative food (innovasi makanan) (Yafie, Suharyono, \& Abdillah, 2016, p. 13). 
1. Freshness yang merupakan salah satu dimensi dari kualitas produk yang perlu diperhatikan oleh tim manajemen dalam industri makanan ini karena adanya kesegaran dalam bahan makanan merupakan sesuatu hal yang sangat penting untuk menjaga kualitas makanan yang akan disajikan untuk pelanggan (p.13).

2. Presentation hal ini merupakan tampilan dari makanan dan pelayanan yang diberikan kepada konsumen. Tampilan makanan yang menarik akan menarik perhatian konsumen dan akan menimbulkan kesan yang baik (p.13).

3. Taste untuk menjaga kualitas makanan dan loyalitas konsumen maka perusahaan harus mempertahankan mutu makanan yang akan disajikan ke konsumen (p.13).

4. Innovative food merupakan keahlian dalam melakukan inovasi seperti pencampuran bahan satu dengan bahan makanan lainnya, variasi rasa (p.13).

Pengertian Jasa atau Pelayanan. Menurut Kotler (2012) dalam (Wijaya, 2018, p. 14) pada buku Manajemen Kualitas Jasa bahwa setiap kegiatan dan tindakan yang ditawarkan pada dasarnya tidak berwujud dan tidak mengakibatkan kepemilikan apapun.

Dimensi pelayanan. Kualitas jasa yang diberikan perusahaan harus mengacu pada standar mutu yang tinggi karena mutu yang tinggi mampu memenuhi harapan konsumen. Dimensi kualitas jasa menurut Kotler dan Keller (2012) dalam (Priansa, 2017, p. 89) terdiri atas sebagai berikut:

1. Tangible (Berwujud), yaitu berkaitan dengan penampilan fasilitas fisik, peralatan, personel, dan media komunikasi (p.89).

2. Reliability (Keandalan), yaitu kemampuan untuk melakukan atau menyediakan jasa yang dijanjikan dengan cepat dan terpercaya (p.89).

3. Responsiveness (Keresponsifan), adalah kemampuan untuk membantu konsumen dan memberikan jasa dengan cepat atau ketanggapan (p.89).

4. Convidence (Keyakinan), yaitu pengetahuan dan kesopanan karyawan serta kemampuan mereka untuk menimbulkan kepercayaan dan keyakinan atau "assurance" (p.89).

5. Empathy (Empati) yaitu, berkaitan dengan kemampuan perusahan dan personelnya untuk merasakan sesuatu yang dirasakan oleh konsumen (p.89).

Loyalitas Pelanggan. Menurut (Griffin, 1995) dalam (Rusydi, 2017, pp. 110 - 111) loyalitas pelanggan adalah mesin penggerak kesuksesan suatu bisnis. Namun usaha mempertahankan konsumen yang merupakan bagian penting dalam menciptakan loyalitas pelanggan bukanlah merupakan hal yang sederhana, karena perusahaan harus mengintegrasikan semua dimensi bisnis dan menentukan bagaimana sebaiknya menciptakan nilai (creating value) bagi konsumennya dengan menciptakan nilai bagi konsumennya akan membangun loyalitas konsumen dan mempertahankannya (Rusydi, 2017, pp. 110 - 111).

Pelanggan yang loyal adalah pelanggan yang selalu setia atau konsisten terhadap produk tersebut dan ini merupakan sesuatu yang patut untuk terus dijaga 
atau diberikan kepuasan untuk memenuhi kebutuhan yang sesuai dengan ekspetasinya. Menurut (Sudaryono, 2016) bahwa konsumen yang loyal adalah konsumen yang menyatakan suka terhadap merek tersebut dan kemudian menggunakannya dengan kata lain loyalitas merek dapat diartikan sebagai pembelian berulang yang terus - menerus atas produk dengan merek yang sama selama kurun waktu tertentu (Sudaryono, 2016, pp. 82 - 83).

Karakteristik Loyalitas Pelanggan. Pelanggan yang loyal bisa dilihat dari karakteristiknya menurut Griffin (2009) mengungkapkan bahwa pelanggan yang loyal memiliki karakteristik, sebagai berikut: (Priansa, 2017, pp. 495 - 496)

1. Melakukan pembelian secara teratur (Makes regular repeat purchase) (p.495).

2. Membeli diluar lini produk/jasa (Purchases across product and service lines) (p.495).

3. Merekomendasikan produk lain (Refers other)(p.495).

4. Menunjukkan kekebalan dari daya tarik produk sejenis dari pesaing (Demonstrates an immunity to the full of the competition) (p.496).

\section{METODE PENELITIAN}

Jenis penelitian yang digunakan adalah korelasional yaitu dalam ilmu statistika istilah korelasi diberi pengertian sebagai hubungan antara dua variable atau lebih (multivariate correlation) (Muhidin \& Abdurahman, 2017, p. 105). Teknik pengumpulan data yang dilakukan oleh peneliti menggunakan kuesioner/angket. Dan juga menggunakan penelitian survei yaitu dilakukan untuk mengumpulkan informasi yang dilakukan dengan cara daftar pertanyaan yang diajukan pada responden. Dalam penelitian survei digunakan untuk meneliti gejala suatu kelompok atau perilaku individu (Tersiana, 2018, p. 16). Maka populasi yang digunakan dalam penelitian ini adalah seluruh konsumen yang pernah melakukan pembelian ulang di Kedai Roti Bakar (Keibar) di Pamulang ukuran rata - rata yang diambil berjumlah 700 orang per minggu. Dengan menggunakan rumus Slovin mendapatkan sampel sebanyak 254 responden.

Teknik pengumpulan data yang dilakukan menggunakan data primer yang digunakan dalam penelitian ini dikumpulkan menggunakan kuesioner yang dibagikan kepada para pengunjung Kedai Roti Bakar (KEIBAR). Dalam penelitian ini teknik dalam pengumpulan data menggunakan kuesioner tertutup, yaitu kuesioner yang sudah disediakan jawabannya oleh peneliti. Responden hanya dapat memilih jawaban yang sudah tersedia pada kuesioner tersebut.Data sekunder yang didapatkan untuk menjalankan sebuah penelitian ini melalui buku, jurnal - jurnal penelitian. Pengumpulan data yang dilakukan juga melalui studi kepustakaan dengan membaca dan memahami buku - buku referensi yang ada. Uji yang digunakan dalam penelitian ini, yaitu uji validitas, uji realibilitas, uji normalitas ( $p$ plot), uji asumsi klasik (multikolinieritsd), uji korelasi berganda dan uji anova (Two Way Anova). Dengan Teknik Analisis Data yang digunakan yaitu Regresi linier sederhana dan Regresi linier berganda (regresi Multivariant).

\section{HASIL DAN PEMBAHASAN}


Karakteristik Responden. Karakteristik responden pada penelitian ini dominan berjenis kelamin perempuan yaitu 128 responden $(50,04 \%)$, sedangkan responden laki - laki yaitu 126 responden (49,06\%). Dengan dominan di usia 21 24 tahun dengan 171 responden (67,03\%). Berdasarkan data tang diperoleh bahwa dominan pelanggan yang loyal terhadap KEIBAR mempunyai pekerjaan sebagai mahasiswa responden yang paling banyak atau dominan sebanyak 143 respoden (56,03\%). Dan, jumlah dominan pelanggan yang melakukan frekuensi kunjungan ke KEIBAR di Pamulang dalam 1 bulan sebanyak 3 - 5 kali dengan total 163 responden $(64,2 \%)$.

Uji Validitas. Dalam penelitian ini $\mathrm{n}=254$ responden dengan taraf signifikansi $5 \%$ atau a $-0,05$. Diperoleh dengan $r$ tabel yaitu $\mathrm{df}=\mathrm{n}-2$ maka $\mathrm{df}=254$ - $2=252$ dan nilai $\mathrm{df}$ adalah 252. Diperoleh $\mathrm{r}$ tabel sebesar 0,103. Menurut (Muhidin \& Abdurahman, 2017, p. 47) dapat dinyatakan valid apabila nilai hitung $r$ tabel lebih besar $(>)$ dari nilai tabel $r$, dan dinyatakan tidak valid apabila nilai hitung $r$ tabel lebih kecil $(<)$ dari nilai tabel $r$. Berdasarkan hasil perhitungan menggunakan SPSS maka dapat disimpulkan bahwa di setiap indicator pada variabel kualitas produk, pelayanan dan loyalitas pelanggan menujukkan hasil yang signifikan dengan nilai hitung $r$ lebih besar $(>)$ dari nilai tabel $r$ yang berarti pernyataan tersebut valid.

Uji Realibilitas. Apabila Alpa Cronbach lebih dari 0,6 pernyataan tersebut dinyatakan reliabel (Siregar, 2013, p. 57). Dalam penelitian ini pada pernyataan variabel kualitas produk (X!) menunjukkan nilai Alpha Cronbach 0,933 yaitu lebih dari 0,6 yang berarti bernilai reliabel. Pada variabel pelayanan (X2) menunjukkan nilai Alpha Cronbach 0,953 yaitu lebih dari 0,6 yang berarti bernilai reliabel. Dan juga pada variabel loyalitas pelanggan (Y) menunjukkan nilai Alpha Cronbach 0,929 lebih dari 0,6 yang berarti bernilai reliable.

Uji normalitas (P-Plot). Pengujian normalitas juga dapat didasarkan pada normal probability. Pengujian dengan data dinyatakan berdistribusi normal apabila titik - titik nilai data terletak kurang lebih dalam suatu garis lurus (Widyanto, 2013, p. 170). Atau Normal P - Plot yaitu penyebaran data terlihat berada di sekitar garis lurus maka dapat disimpulkan bahwa sebaran data normal dan ini berarti syarat normalitas data terpenuhi (Nisfiannoor, 2019, p. 170). 


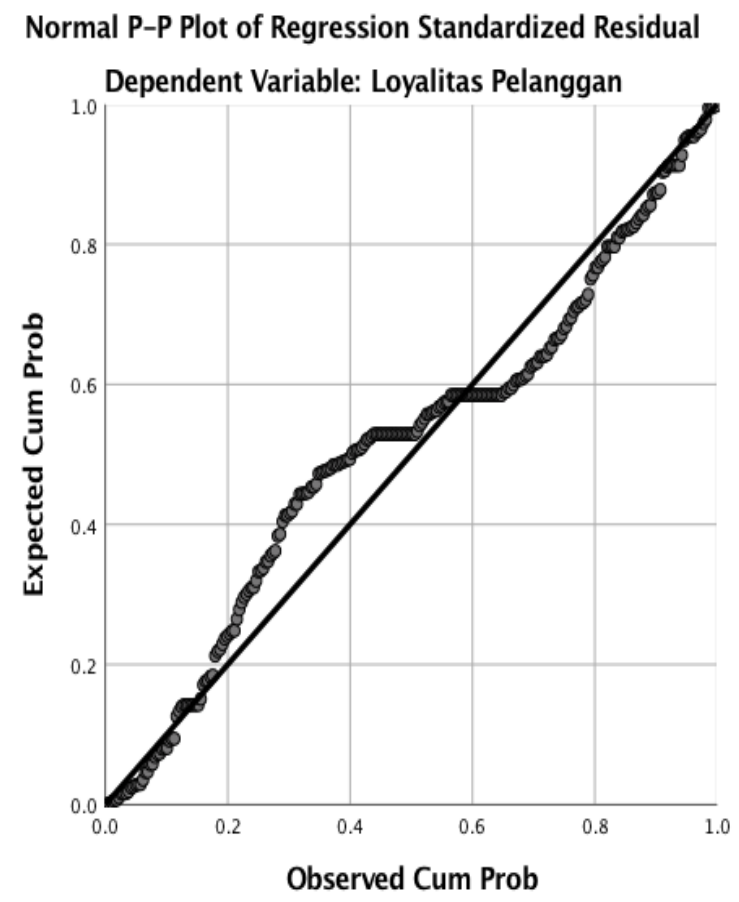

Gambar 1. Grafik P - Plot Dependen Variabel Data Olahan Peneliti, 2019

Berdasarkan gambar grafik Normal P - Plot diatas terlihat titik - titik yang mengikuti dan mendekati garis diagonal sehingga menunjukkan pola distribusi normal maka model regresi memenuhi asumsi normal.

\section{Uji Korelasi Ganda}

Tabel 1. Uji Korelasi Berganda

\begin{tabular}{|c|c|c|c|c|c|c|c|c|c|}
\hline & \multicolumn{9}{|c|}{ Model Summary } \\
\hline \multirow[t]{2}{*}{ Model } & $\mathrm{R}$ & $\begin{array}{c}\mathrm{R} \\
\text { Sayare }\end{array}$ & $\begin{array}{c}\text { Adjust } \\
\text { ed R } \\
\text { Souar }\end{array}$ & $\begin{array}{c}\text { Std. } \\
\text { Error } \\
\text { of the }\end{array}$ & & Char & se $S t$ & atisti & \\
\hline & & & & & $\begin{array}{c}\mathrm{R} \\
\text { Square } \\
\text { Change }\end{array}$ & $\begin{array}{c}\mathrm{F} \\
\text { Change }\end{array}$ & $\begin{array}{c}\mathrm{df} \\
1\end{array}$ & $\mathrm{df} 2$ & $\begin{array}{c}\text { Sig. F } \\
\text { Chan } \\
\text { ge }\end{array}$ \\
\hline 1 & .798 & .637 & .634 & $\begin{array}{c}398.62 \\
6\end{array}$ & .637 & $\begin{array}{c}220.02 \\
0\end{array}$ & 2 & $\begin{array}{c}25 \\
1\end{array}$ & .000 \\
\hline
\end{tabular}

a Predictors: (Constant), Pelayanan, Kualitas Produk

Sumber : Data Olahan Peneliti, 2019

Bahwa Kualitas Produk (X1) dan Pelayanan (X2) mempunyai nilai R sebesar 0,798 Sehingga menujukkan korelasi yang terjadi antara variabel independent (kualitas produk (X1) dan Pelayanan (X2)) dengan variabel dependent (Loyalitas Pelanggan (Y)) menujukkan pengaruh korelasi yang kuat $(0,600-0,798)$. 
Diperoleh nilai poboabilitas (sig. $\mathrm{F}$ change) $=0,000$. Karena nilai sig. $\mathrm{F}$ change $0,000<0,05$, maka keputusannya adalah Ho ditolak dan Ha diterima. Sehingga kualitas produk dan pelayanan berhubungan secara stimulant dan signifikan terhadap loyalitas pelanggan pada Kedai Roti Bakar (KEIBAR) di Pamulang.

\section{Uji Anova}

Tabel 2. Hasil Uji Anova Antara Variabel Kualitas Produk (X1) dan Pelayanan (X2) Terhadap Loyalitas Pelanggan (Y)

\begin{tabular}{clccccc}
\hline \multicolumn{7}{c}{ ANOVA $^{\text {a }}$} \\
\hline Model & & $\begin{array}{c}\text { Sum of } \\
\text { Squares }\end{array}$ & df & $\begin{array}{c}\text { Mean } \\
\text { Square }\end{array}$ & F & Sig. \\
\hline 1 & Regression & 6.992 .376 & 2 & 3.496 .188 & 220.020 & $.000^{\mathrm{b}}$ \\
\hline & Residual & 3.988 .463 & 251 & 15.890 & & \\
\hline & Total & 10.980 .839 & 253 & & & \\
\hline
\end{tabular}

a Dependent Variable: Loyalitas Pelanggan

b Predictors: (Constant), Pelayanan, Kualitas Produk

\section{Sumber : Data Olahan Peneliti, 2019}

Dapat dilihat dari tabel Anova tersebut bahwa hasil penelitian diatas menyatakan bahwa nilai signifikansi adalah 0,000 yang mempunyai arti lebih kecil dibandingkan nilai probabilitas yaitu sebesar 0,05. Apabila nilai signifikan $<0,05$, berarti Ho ditolak dan Ha diterima. Sebaliknya, jika nilai signifikan $>0,05$, maka Ho diterima dan Ha ditolak. Dengan demikian, dapat disimpulkan bahwa model persamaan regresi berdasarkan penelitian ini adalah signifikan.

Hal ini memiliki pengertian bahwa Ho ditolak dan Ha diterima, dikarenakan hasil tersebut maka dapat disimpulkan bahwa terdapatnya pengaruh kualitas produk dan pelayanan terhadap loyalitas pelanggan.

\section{Hasil Analisis Regresi Sederhana (X1 dan Y)}

Tabel 3. Regresi Sederhana Coefficients X1 dan Y

\begin{tabular}{|c|c|c|c|c|c|c|}
\hline \multicolumn{7}{|c|}{ Coefficientsa } \\
\hline \multirow{2}{*}{\multicolumn{2}{|c|}{ Model }} & \multicolumn{2}{|c|}{$\begin{array}{l}\text { Unstandardized } \\
\text { Coefficients }\end{array}$} & \multirow{2}{*}{$\begin{array}{l}\begin{array}{c}\text { Standardized } \\
\text { Coefficients }\end{array} \\
\text { Beta }\end{array}$} & \multirow[b]{2}{*}{$\mathrm{t}$} & \multirow[b]{2}{*}{ Sig. } \\
\hline & & B & Std. Error & & & \\
\hline \multirow[t]{2}{*}{1} & $\begin{array}{c}\text { (Constant } \\
\text { ) }\end{array}$ & 6.619 & 2.120 & & 3.123 & .002 \\
\hline & $\begin{array}{l}\text { Kualitas } \\
\text { Produk }\end{array}$ & .779 & .042 & .760 & 18.542 & .000 \\
\hline
\end{tabular}

Sumber : Data Olahan Peneliti, 2019 
Nilai konstanta sebesar 6.619 menyatakan bahwa nilai yang terdapat pada variabel Kualitas Produk (X1), maka nilai Loyalitas Pelanggan (Y) adalah 6.619. Sedangkan, untuk koefisien regresi sebesar 0,779, dimana setiap penambahan nilai (positif) Loyalitas Pelanggan akan memeberikan penurunan 0,779 terhadap Kualitas Produk.

\section{Hasil Analisis Regresi Sederhana (X2 dan Y)}

Tabel 4. Regresi Sederhana Coefficients X2 dan Y

\begin{tabular}{|c|c|c|c|c|c|c|}
\hline \multicolumn{7}{|c|}{ Coefficients $^{a}$} \\
\hline \multirow[t]{2}{*}{ Model } & & \multicolumn{2}{|c|}{$\begin{array}{c}\text { Unstandardized } \\
\text { Coefficients }\end{array}$} & \multirow{2}{*}{$\begin{array}{c}\text { Standardized } \\
\text { Coefficients } \\
\text { Beta }\end{array}$} & \multirow{2}{*}{$\mathrm{t}$} & \multirow{2}{*}{ Sig. } \\
\hline & & B & $\begin{array}{l}\text { Std. } \\
\text { Error }\end{array}$ & & & \\
\hline \multirow[t]{2}{*}{1} & (Constant) & 7.968 & 2.210 & & 3.605 & .000 \\
\hline & Pelayanan & .560 & .033 & .734 & 17.167 & .000 \\
\hline
\end{tabular}

Sumber : Data Olahan Peneliti, 2019

Nilai konstanta sebesar 7.968 menyatakan bahwa nilai yang terdapat pada variabel Pelayanan (X2), maka nilai Loyalitas Pelanggan (Y) adalah 7.968. Sedangkan, untuk koefisien regresi sebesar 0,560, dimana setiap penambahan nilai (positif) Loyalitas Pelanggan akan memeberikan penurunan 0,560 terhadap Pelayanan.

\section{Regresi Linier Berganda}

Regresi linier berganda digunakan untuk menganalisis pengaruh kualitas produk (X1), pelayanan (X2) terhadap loyalitas pelanggan (Y) pada Kedai Roti Bakar (KEIBAR) di Pamulang.

Tabel 5. Hasil Rangkuman Uji Regresi Berganda Variabel X1, X2, dan Y

\begin{tabular}{ccccc}
\hline \multicolumn{4}{c}{ Model Summary } \\
\hline Model & $\mathrm{R}$ & $\begin{array}{c}\mathrm{R} \\
\text { Square }\end{array}$ & $\begin{array}{c}\text { Adjusted } \\
\text { R Square }\end{array}$ & $\begin{array}{c}\text { Std. Error of the } \\
\text { Estimate }\end{array}$ \\
\hline 1 & $.798^{\mathrm{a}}$ & .637 & .634 & 398.626 \\
\hline a Predictors: (Constant), Pelayanan, Kualitas Produk \\
b Predictors: (Constant), Pelayanan, Kualitas Produk
\end{tabular}

Sumber : Data Olahan Peneliti, 2019 
Berdasarkan tabel di atas dapat dilihat bahwa besaran variasi perubahan pada variabel Kualitas Produk (X1) dan Pelayanan (X2) yang ditentukan oleh variabel Loyalitas Pelanggan $(\mathrm{Y})$ adalah sebesar 0,634 atau 63,4\%, dimana sisanya sebesar $36,6 \%$ (100\% - 61,4\%) dipengaruhi oleh faktor lain diluar dalam penelitian ini.

Tabel 6. Hasil Koefisien Uji Regresi Berganda Variabel X1, X2, dan Y

\begin{tabular}{rlccccc}
\hline \multicolumn{7}{c}{ Coefficients $^{\mathrm{a}}$} \\
\hline Model & & \multicolumn{2}{c}{$\begin{array}{l}\text { Unstandardized } \\
\text { Coefficients }\end{array}$} & $\begin{array}{l}\text { Standardized } \\
\text { Coefficients }\end{array}$ & $\mathrm{t}$ & Sig. \\
\hline & $\mathrm{B}$ & $\begin{array}{l}\text { Std. } \\
\text { Error }\end{array}$ & Beta & & \\
\hline 1 & (Constant) & 1.965 & 2.097 & & .937 & .350 \\
\hline & $\begin{array}{l}\text { Kualitas } \\
\text { Produk }\end{array}$ & .490 & .060 & .477 & 8.218 & .000 \\
\hline & Pelayanan & .285 & .044 & .373 & 6.424 & .000 \\
\hline
\end{tabular}

a Dependent Variable: Loyalitas Pelanggan

Sumber : Data Olahan Peneliti, 2019

$\mathrm{Y}=\mathrm{a}+\mathrm{b}_{1} \mathrm{X}_{1}+\mathrm{b}_{2} \mathrm{X}_{2}$

$Y=1.965+0,490 X_{1}+0,285 X_{2}$

Dari hasil persamaan regresi linier berganda, dapat diketahui bahwa nilai konstanta (a) sebesar 1.965 yang menunjukkan nilai positif yang menandakan bahwa terdapat kenaikan nilai pada variabel Kualitas Produk (X1) dan Pelayanan (X2), maka nilai yang terdapat pada variabel Loyalitas Pelanggan (Y) adalah 1.965. sedangkan, nilai pada koefisien regresi sebesar 0.490 dan 0.285 bernilai positif yang menunjukkan bahwa adanya kenaikan pada nilai Kualitas Produk dan Pelayanan akan memberikan peningkatan satu - satuan pada Loyalitas Pelanggan yaitu 0.490 dan 0.285 .

\section{KESIMPULAN}

Berdasarkan penelitian yang telah dilakukan oleh peneliti dalam bab satu penelitian yaitu "Kualiitas Produk dan Pelayanan Terhadap Loyalitas Pelanggan pada Kedai Roti Bakar (KEIBAR) di Pamulang", dapat ditarik kesimpulan sesuai dengan tujuan penelitian sebagai berikut:

1. Kualitas Produk berpengaruh pada loyalitas pelanggan dengan nilai 0,779 .

2. Pelayanan berpengaruh pada loyalitas pelanggan dengan nilai regresi 0,560.

3. Kualitas produk dan pelayanan memiliki hubungan yang kuat terhadap loyalitas pelanggan dengan nilai regresi 0,634.

\section{DAFTAR PUSTAKA}


Aryani, D., \& Rosinta, F. (2010, Mei - Agustus). Pengaruh Kualitas Layanan terhadap Kepuasan Pelanggan dalam Membentuk Loyalitas Pelanggan. Jurnal Ilmu Administrasi dan Organisasi Program Studi Ilmu Administrasi Departemen FISI, Universitas Indonesia, 17, 115.

Erica, D., \& Rasyid, H. A. (2018). Pengaruh Kualitas Layanan Dan Pemanfaatan Teknologi Informasi Terhadap Kepuasan Dan Loyalitas Pelanggan Jasa Transportasi Online Di Jakarta. Amik BSI Jakarta, XVI(2), 169.

Hardiyansyah. (2018). Kualitas Pelayanan Publik. Yogyakarta: Gava Media.

Kennedy, J. E., \& Soemanagara, R. D. (2009). Marketing Communication Taktik dan Strategi. Jakarta: PT Bhuana Ilmu Populer.

Kotler, P., \& Keller, K. L. (2009). Manajemen Pemasaran, Edisi Ketiga Belas Jilid 1. (A. Maulana, W. Hardani, Eds., \& B. Sabran, Trans.) Jakarta: Erlangga.

Muhidin, S. A., \& Abdurahman, M. (2017). Analisis Korelasi, Regresi, dan Jalur dalam Penelitian (Dilengkapi Aplikasi Program SPSS). Bandung: CV Pustaka Setia.

Nisfiannoor, M. (2019). Pendekatan Statistika Modern Untuk Ilmu Sosial. Jakarta: Salemba Humanika.

Priansa, D. J. (2017). Komunikasi Pemasaran Terpadu. Bandung: CV Pustaka Setia.

Putro, S. W., Semuel, H., \& Brahmana, R. K. (2014). Pengaruh Kualitas Layanan Dan Kualitas Produk Terhadap kepuasan Pelanggan Dan Loyalitas Konsumen Restoran Happy Garden Surabaya. Jurnal Manajemen Pemasaran Jurusan Manajemen Pemasaran, Universitas Kristen Petra, 2(1), 1.

Rusydi, M. (2017). Customer Excellence. Yogyakarta: Gosyen Publishing.

Siregar, S. (2013). Metode Penelitian KUANTITATIF. Jakarta: PRENADAMEDIA GROUP.

Sudaryono. (2014). Perilaku Konsumen. Jakarta Pusat: Lentera Ilmu Cendekia.

Sudaryono. (2016). Manajemen Pemasaran. Yogyakarta: ANDI.

Tersiana, A. (2018). Metode Penelitian. Yogyakarta: Start Up.

Tjiptono, F. (2015). Strategi Pemasaran Edisi 4. Yogyakarta: CV. ANDI OFFSET.

Wijaya, T. (2018). Manajemen Kualitas Jasa (Edisi Kedua ed.). Jakarta Barat: PT Indeks .

Widyanto, M. A. (2013). Statistika Terapan : Konsep \& Aplikasi SPSS dalam Penelitian Bidang Pendidikan, Psikologi \& ilmu Sosial Lainnya. Jakarta: PT Elex Medua Komputindo.

Yafie, A. S., Suharyono, \& Abdillah, Y. (2016). Pengaruh Kualitas Produk Dan Kualitas Jasa Terhadap Kepuasan Pelanggan (Studi Pada Pelanggan Food And Beverage 8 OZ Coffee Studio Malang). Jurnal Administrasi Bisnis (JAB), Fakultas Ilmu Aadministrasi, Universitas Brawijaya, 35(2), 13. 